\title{
Queer Youth on the Move: Gentrification and the International in Beijing
}

\section{Thomas Elias Siddall 劉夢飛}

\section{University of Toronto}

Thomas is an undergraduate student and researcher at the University of Toronto. They research community and solidarity as movements of postmemory and respacialization, in the Sinosphere and across the global Chinas. They are interested in queer politics and how the global politics of space, border and belonging shape narratives of home.
Keywords

Migration, Gentrification, Queer Communities, Youth, Beijing. 


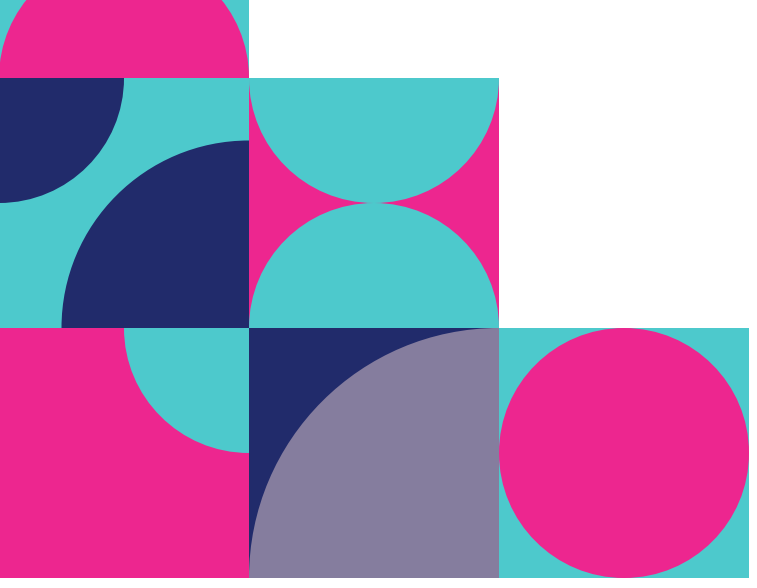

\section{Abstract}

This article presents an autobiographical study of shifting queer formations in northeastern Beijing where the author participated in clubbing rituals and lived amongst members of Beijing's queer communities. This resulted in a study of globalization and the Chinese state's gentrification tactics which co-opt transgressive energy to infiltrate and dominate local queer spaces. Local and migrant queer bodies are using transnational means and techniques in claiming autonomy while continuously forming social spaces that subvert central power structures through affective power. These reterritorializations are then subject to global LGBT discourse, which uses gentrification of space as a form of constituting proper behaviour. Gentrification, as an international process, demands subversive energy and action in response, which ultimately defines queer youth as worthy of autonomy. These findings have research possibilities in developing Sino-queer migration within a post-positivist international relations and multiplex theory research program.

"I know. It's not fair that the word laughter is trapped inside slaughter."

- Ocean Vuong 
Getting off the Beijing Subway's Line Ten at Liangmaqiao Station 亮马桥占, one of Beijing's ring road subways, places you just north of glittering Sanlitun, Beijing's highlighted nightlife core that is a manifestation of China's rapid development in the past 40 years. Walk twenty minutes from here through a few alleyways, however, and you will find the lights of gentrified Sanlitun Village 三里屯 and Taikoo Li 太古里一which exemplifies the repurposing and renovation of space into one suitable for valorized lifestyles and the subsequent psychological changes that people endure-go from coloured and bright to the yellow-tinted streetlamps of Chinese cities indicating that northeast Beijing at night is not for tourists. This area of Beijing was formerly the Dashanzi 大山子 industrial area. Sixty years of history in this area, applying the narratives and experiences of gentrification, highlight how the Chinese state's renovation of its capital intersects with queer migration and subversion through nightlife; these intersections capture, territorialize and reterritorialize creative and transgressive energy. Gentrification is a result of Chinese globalization, which also subjects local queer communities to global LGBT discourse which challenges local identities. Through these experiences, displacement and resistance are at the core of local queer community-building.

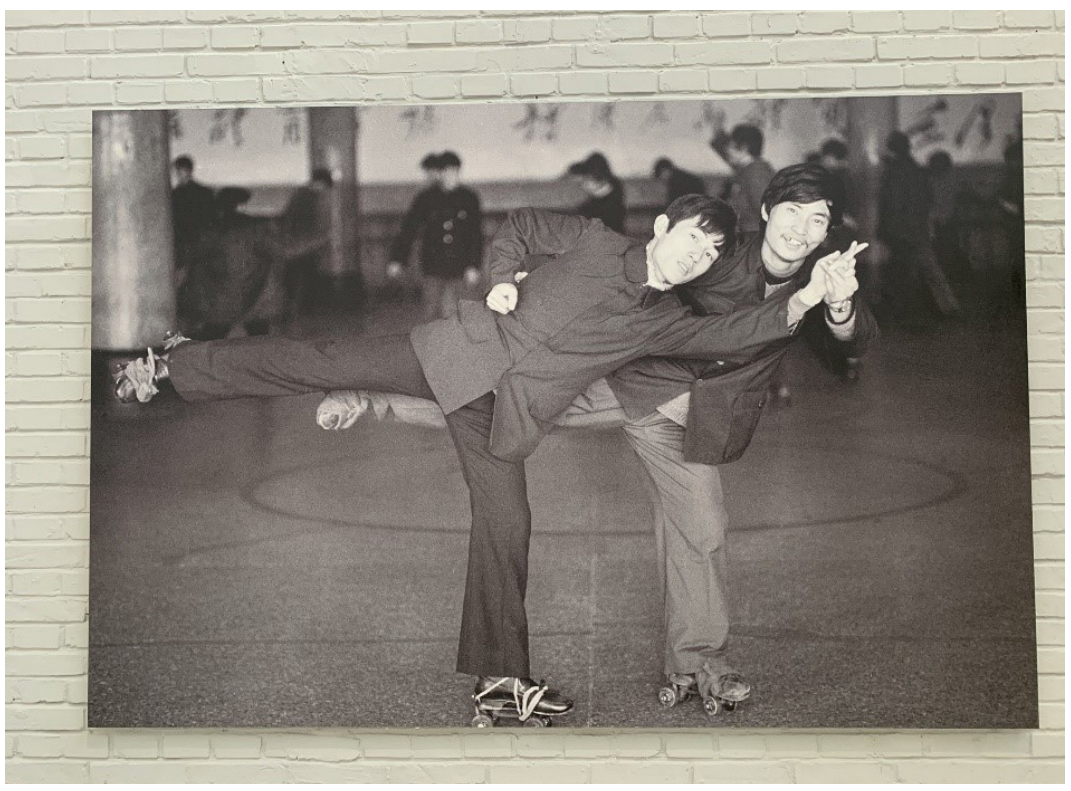




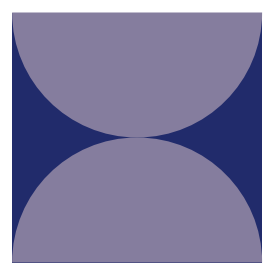

\section{The Gentrification of 798: Intrusion, Transition, Expulsion}

798 Art District 七九八艺术区, a constituent of Dashanzi in northeastern Beijing, is backdropped against a Mao-era factory park. It serves to centralize the context of this article and presents us with a developmental story that highlights the rapidness of state-led gentrification in Beijing.

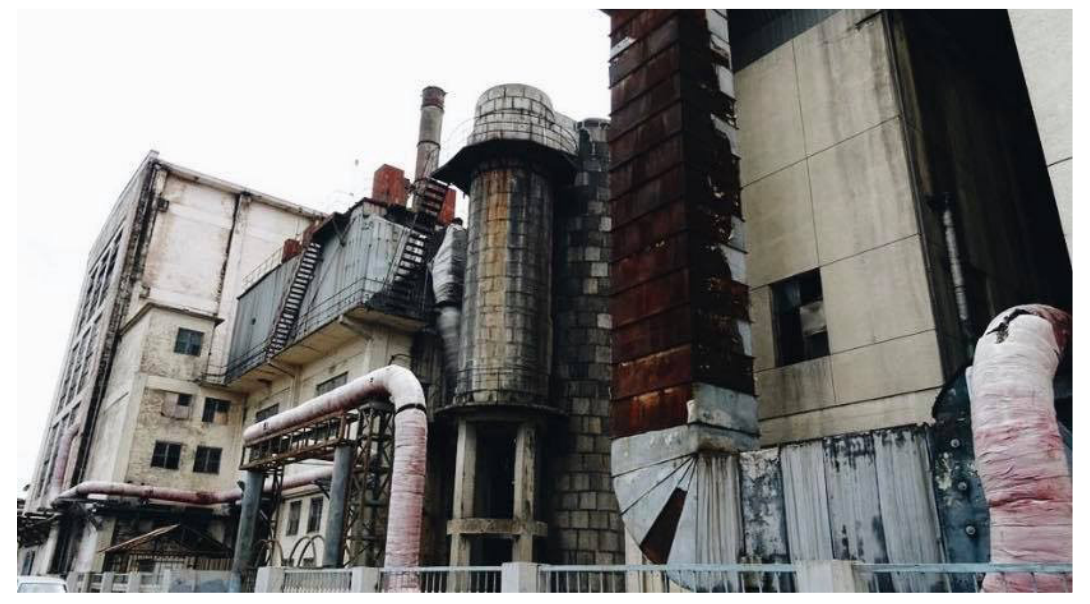

Mao-era factory in Dashanzi

Dashanzi's subsequent metamorphosis into its present cosmopolitan space is a result of increased consumption, but also reflects and produces a specific heteronormative history of contemporary China. 798 is a story I have experienced and, in my memory, its history highlights the political context of Chinese gentrification in a world that has imposed new neoliberal visions of modernity as the responsibility of a hegemonic state that dominates space and time.

During the Great Leap Forward (1958-1962), state-led development prioritized urbanization through the production of steel and other manufactured textiles, which saw the rise of Dashanzi as a result of rapid migration from rural areas to urban cores. Critically, this project saw one of the worst human-made famines due to reductions in labour on farms, communal dining practices, and the "deprivation of peasants' rights to exit from the commune," which had the effect of destroying productivity (Li \& Yang 2005). With the opening of China after the death of Mao, Chinese steel production slowed down and the eventual surplus of steel brought many of these factories to a close. These factories became dilapidated once they fell out 
of use, and Dashanzi eventually became populated by artists, queer people, and other migrants attracted by cheap land prices and proximity to the capital. The area is one of migrants and it is a fully functioning community. Ai Weiwei 艾未末 (b. 1957) was one of the area's most notorious residents and his home and studio employed many migrants. Other migrants work in informal work. In 2006, I remember this area still being "antiquated" and the central government did not have any incentive to gentrify the area, opting to let the residents live outside of the state's gaze.

Backdropped against Maoist slogans, cultural occasions such as the Beijing Queer Film Festival, proliferated a culture that appeared organic in its autonomy but laid down the roots and precedence for the encroachment of the state into the affairs of people who lived here. By the end of 2006, developments for the 2008 Beijing Olympic games saw the rapid closure of factories to clean Beijing's notoriously bad air pollution. The subsequent rapid urban gentrification that happened came in the context of a complex and violent capitalist political economy that was directly related to China's position within the global economy. China would be the first "developing" country in the world to host the Olympics, and so it needed to showcase its "modernity," with a clean and developed city. Ai Weiwei became the artistic consultant for the Bird's Nest 鸟巢 (now the National Stadium 国际体育场) bringing attention to a prolific artistic movement in Beijing. This coincided with a transition from the industrial manufacturing sector to an economic model that turned artists into the primary economic model for Dashanzi and helped to bring about a renaming of this area as the "798 Art District." This model borrows from Richard Florida's Rise of the Creative Class (2012), where he posits that the creative class (artists, tech designers, LGBT people, etc.) are the key to growth in post-industrial cities. For 798 , the economic model posited by Florida is clearly applied as it transitions from an industrial site into one where factories 
became galleries and workshops for artisans, which supports the economic hub of Guomao 国贸, just south of 798 .

In 2015, gentrification continued in 798 and resulted in the demolition of migrant homes and the development of art galleries as shopping centres. Ai Weiwei also left China in 2015. This shift, which brought state intrusion into northeastern Beijing, took less than a decade. It occurred at the same time as the priorities of the central government moved from an investment-driven economy into one that was driven by consumption. Not just in 798 but in cities across China, the sheer

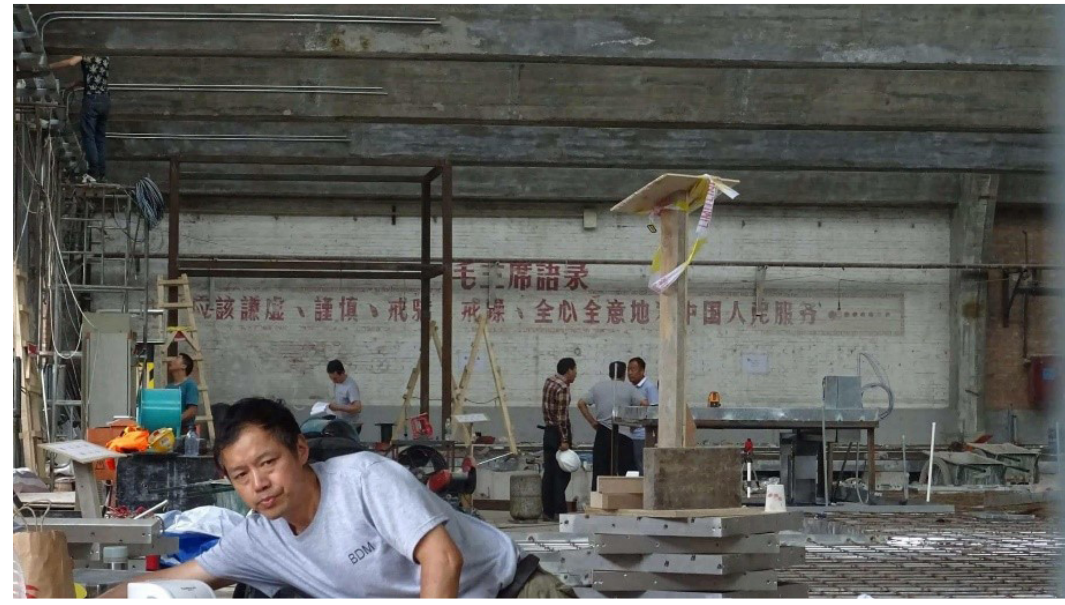
number of advertisements highlight how capitalist advertising replaced Maoist propaganda. Interestingly, a form of Chinese Pop Art that was centred upon minions, who are yellow alien-like characters from the movie Despicable Me, was painted on renovated factories an art gallery in a Mao-era as a political statement factory in 798 against gentrification which turned migrant homes and artist workshops into copy and paste shopping malls that dot Beijing's and other cities' landscapes, while simultaneously mocking the design of this gentrification.

Consumption became a significant issue for the central government because as China's economy began to show signs of a slowdown, the increasing inefficiency of investments towards low-end goods production led the state to supplement these declining investments with domestic consumption. Most economists agree that consumption as a percent of income needs to be expanded from its present levels of around $29 \%$ to $60 \%$ by 2027 . That level of consumption would require income inequality to be 
level so that China not be constrained by the middleincome trap (Glawe and Wagner 2019; Zhou 2018; Huang 2015). The gentrification of Dashanzi serves a political purpose for the central government as a means of avoiding the middle-income trap in order to maintain consent for the increasing domination of state hegemony as the state produces visions of economic success through the renovation of its cities.

By 2019, 798 visibly had more shops than art galleries. It is a place where you can expect to shop for Louis Vuitton rather than taking in art; the art galleries that do exist hold art for sale, with an equal amount of QR codes, which have proliferated as point-of-sale tools in China due to the lack of credit cards, as installation. I went into a tiny gallery with two sculptures in it, one of the only galleries to not have a QR code and I asked the artist why she did not sell her work, and she said because her "art was for art, and this is a form of subversion in China's market economy," where citizenship, personhood and recognition is necessarily dependent upon purchasing power. The gentrification of 798 effectively destroyed the socialization and solidarity between artists, migrants and queer people by turning "third spaces," of which the feeless art galleries used to be, into places inaccessible to people living in the area, who cannot afford access. The complexities that create this state-led capitalist system have brought about an extraordinarily simplistic and brutal destruction of a known way of living for residents of 798/Dashanzi. To put on an art show rejecting the market co-opts energies of expulsion, which is the same energy that gentrification uses. Northeast Beijing has shown itself to be a site of protest for bodies against an intrusive gentrification that expels those who have made community there; it is ultimately a subversion of hegemony, the same which queer youth are continuing with their presence and protests in northeastern Beijing by building their autonomy in a newly dominated territory. 


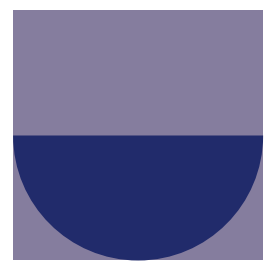

\section{Laughter: Tactics of Building Local Queer Space for Globally Minded Youth}

Zhaodai 招待听 (which means guesthouse), a queer club, is part of the rebirth of the protest of the new political economy in northeastern Beijing. One night my friends, who attend Renmin University, invited me to an underground rave held by the Beijing LGBT Center to celebrate the beginning of Pride month. Zhaodai is an informal space where local Chinese queer communities come to be themselves. They are part of a significant global trend away from the "gay club" to the "queer space," partially as a result of global patterns of gentrification. However, engendering queer spaces bring about a necessity to connect to the world as uniquely queer and Chinese is necessitated by an ever-encroaching

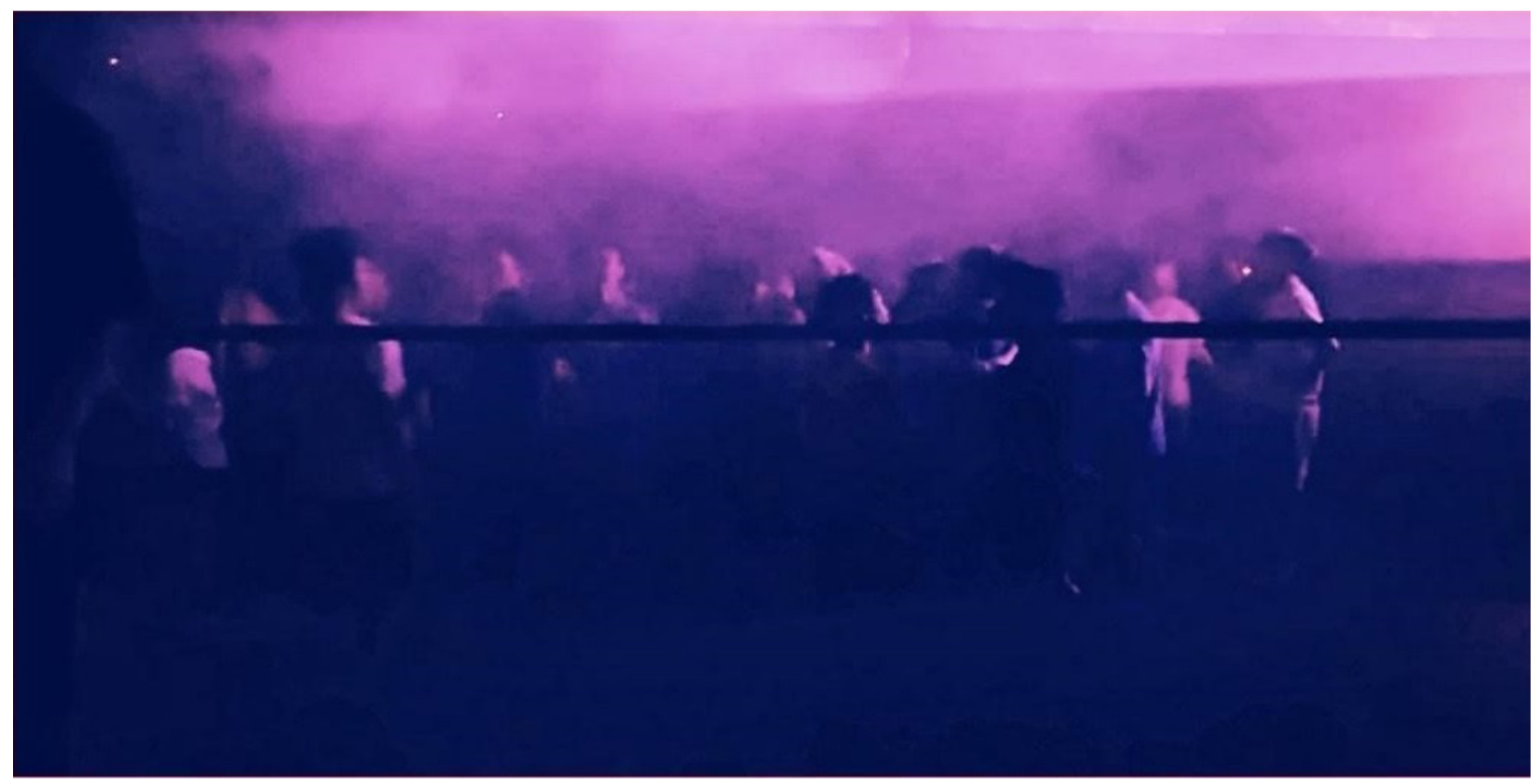

Zhaodai an informal queer celebrating the beginning of Pride Month state. The mission of Zhaodai is to "cultivate club culture and strengthen the community behind it." Part of the queer milieu in today's China is looking to the artistic roots of northeastern Beijing in the formation of symbols and signs such as Ren Hang. Zhaodai, as a queer space, is a technicolour shrine to Ren Hang 任航 (1987-2017) who died at age 29, sending shockwaves throughout international artistic 
communities, but went relatively unknown in his native China. Ren's photos are filled with shock value: they express sexuality, contortion, nudity and are raw yet playful. Never personally political, he has said that "my pictures' politics have nothing to do with China. It's Chinese politics that wants to interfere with my art." (Kane 2015). Supported by Ai Weiwei, Ren was part of the generation of queer artists based out of 798 who used art for activism, and yet became lost along with 798 and its gentrification. Queer youth at Zhaodai signify using Ren's art as a declaration that autonomy of artists, of migrants, and of queer people has come to an end; to be queer in today's Beijing is to territorialize both the space and bodies of formerly autonomous peoples.

Zhaodai was evidently trying to be hidden, given its placement in the basement of a soba noodle restaurant, its two sets of staircases, three sets of blackout and soundproof doors, a lack of signage, and its purposeful distance away from any subway line. However, it was still navigable by locals and foreigners alike. That June night was the beginning of Pride celebrations in Beijing, which still carry the grassroots formations and local queer cultures that many other cities' Pride festivities lack. Zhaodai and the Beijing LGBT Center organized this night without any local permits. Getting into the club, fluorescent paint was smeared with a powerful stroke onto patrons' faces. My friends and others went into the bathroom to change their earrings to ones that would have marked them as different outside of this space. This powerful moment of transition and change is representative of the power held within spaces of solidarity built by and for local queer youth. This simple yet powerful transition of changing clothes occurred often, yet paradoxically, friends have told me they could have dressed up in public, but it would have been considered odd.

Foreigners who come to Zhaodai are rarely tourists but are more likely to be queer youth from 
around the Sinosphere. Even though this place was hidden, Zhaodai did have an online following through Instagram, which allowed it to connect to an Internet that was not easily accessible to many mainland Chinese people. This brings an international dimension to Beijing queer youths' subversiveness. The use of Instagram and other nominally blocked off social media by queer youth in Beijing and China alike is widespread, and it is done to become informed of the transnational aspects of community building. With this, Zhaodai allows you to explore an informal side to the queer communities of Beijing, one deeply marked by transnational migration and organization through digital spaces. By existing in the digital space while hiding in an increasingly gentrified social space, queer youth are exhibiting an act of power by reterritorializing a dominant territory without demanding to be heard-only to reclaim a rapidly declining autonomy. This digital space, as a way of bringing in non-Beijing queer youth, links the overall global resistance to gentrification with new modes of counterhegemonic organizing.

While the digital space is an attractive motivator for queer youth to move to or even visit Beijing for an extended period, there are numerous other reasons that queer youth are moving to Beijing, which include the recognition and understanding of pluralistic gender identities and geopolitical circumstances. One patron said that they came to China from California because it was more comfortable to express their non-binary gender identity here than back home with a mother who did not accept or make an attempt to understand them. They were an androgynous presenting person, and they said that they felt androgyny while being fetishized in Western queer spaces created a voiceless position for them. The existence of androgynous people in China has been commonplace amongst queer and non-queer spaces. The 2SLGBTQ+ movement in the United States has had a particular exclusion of non-binary gendered people/agender people, which is foiled directly by the 
American understanding of gender and sex as existing in a binary. We later met Taiwanese patrons whom my friends had met on Blued, a Chinese dating/hookup app for gay men, and even though Taiwan is a beacon of LGBT rights in Asia, geopolitical circumstances are still bringing queer Taiwanese people to China. Taiwanese people can find employment in Beijing, and the linguistic barrier is minimal. However, the profound presence of Taiwanese people in these Chinese spaces provides the possibility of analysis of Sino-queer movements based on cross-strait migration. Zhaodai finds itself with a diverse group of people, signalling that solidarity, outreach and informality bring an energy to northeastern Beijing that makes it a transnational migratory hub for the world through complex respacialization, which redefines the space and its purpose.

Queer transnationalism is a diverse process that uses varied tactics to carve out space, and it is a necessity for the survival of local queer spaces in Beijing. Queer transnationalism in the West is understood in the form of asylum claims for queeras-LGBT people. However, there are deeper economic ties that shape communities abroad through the economic proliferation of queer people.

At Zhaodai, I met an English-speaking patron from the Philippines and a bartender from Gansu province, both of whom were in sex work. When asked why they would come to Beijing, both mentioned that they were no longer working in the construction labour field where many migrant workers find employment within China, but still stayed around because they made more money and had community ties, which was more than what they had back home. When asked about their family situations, they mentioned that being away had helped their family to begin to understand them and to accept their queer identities. Migrant economic gains and remittances show that queer transnationalism in Beijing is part of a global remittance system of 
poverty relief. This system directly affects migrants' social situations at home as remittance payments from migrating workers back to their country of origin can have a positive effect on offsetting poverty (Wood 2016). Through this rationale of queer transnationalism, sex workers and the queer club in Beijing become centres for changing attitudes about queer people in other places around the world.

By connecting to transnational queer flows through the rise of digital connectivity, Zhaodai and queer youth in Beijing are building spaces that verify themselves as connected to the artistic movement in northeastern Beijing. This verification is seen in the development and communal understanding of signs, such as in Ren Hang's work, which marks off queer spaces. However, the gentrification of 798 and the subsequent death of a non-consumerist based artistic movement can simultaneously be seen as an encroachment on queer community building. Gentrification deserves more attention when noting that once it becomes saturated with global discourse, such as LGBT discourse, it takes on a new and violent meaning that marginalizes certain bodies for needing to improve themselves.

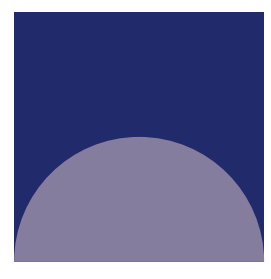

\section{Other (Global) Queers: The Normalization of LGBT Discourse}

While the informal queer club of Beijing exemplifies how migration has played a role in creating a hotbed of activity, neoliberal globalization demands the categorization of "normal" queers through the proliferation of LGBT discourse which seeks to know diverse sexualities through LGBT lenses. This occurs through gay tourism and/or temporary work permits in fields like English teaching. As a result, local queer communities are being remoulded by the demands of the renovating and globalizing state. 
In learning more about gentrification, I visited another club called Destination, which is licenced. I met up with a Shanghai and Hong Kong-based model from Grindr, who was from Ottawa, as well as two people from Macao, three from Hong Kong and one from South Africa - all of whom were there temporarily. It is not so much the space of Destination that makes it an inviting space, but instead what it is not. When Destination closed for the night, we left for a closed off-site of what was the old location of an informal club called Kai for an afterparty at the recommendation of one of the club attendants. Kai was shut down as a result of gentrification and

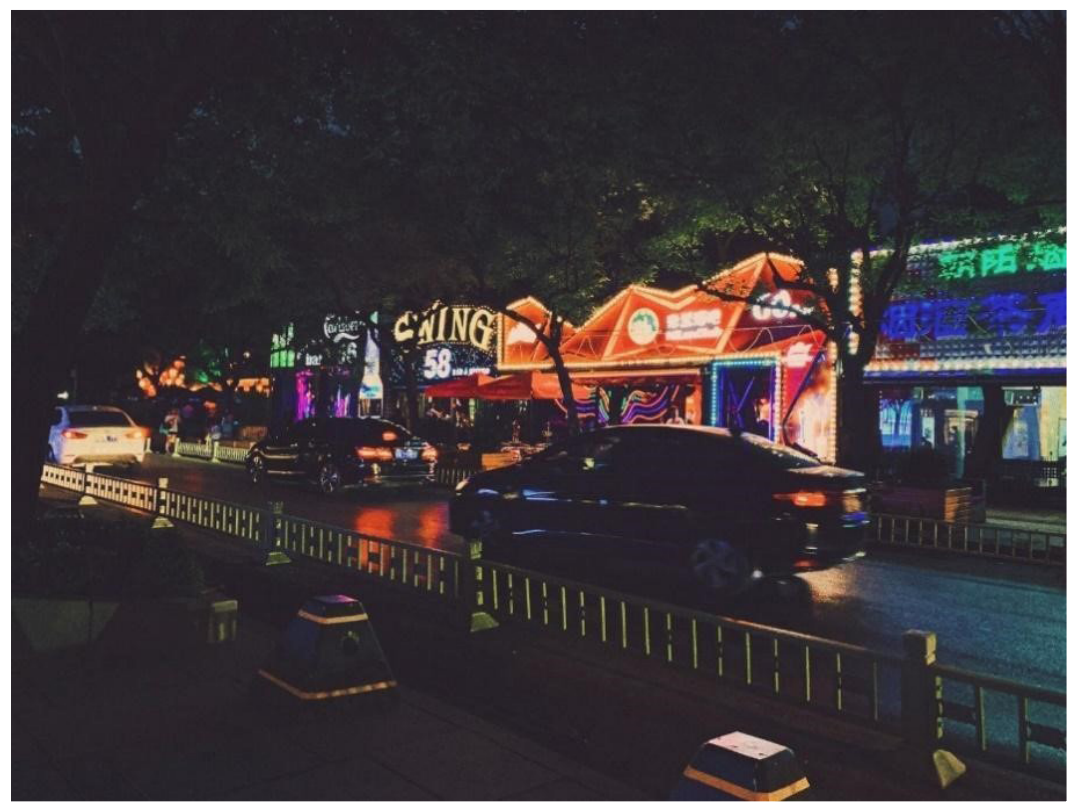

Bar Street 酒吧街, Sanlitun District. well-lit area in contrast to Destination. was now a construction site. The act of having an afterparty on the graveyard of an old, favoured gay club is an act of protest and an act of informality in the reclamation of safe spaces. Kai, as of writing, has reopened but remains an unlicensed club in a new location in the northern part of Dongsi 东四, a central area of Beijing. The world's penetration into informal spaces in Beijing is a function of China's integration into the world migratory system and it also speaks to the openness to migrants of local queer youth in China. However, this openness does not extend to Western and LGBT actors whose proliferation has led to a crackdown on local queer spaces.

Gentrification works as a policing mechanism in which local queer solidarity and community-building is broken down. Queer solidarity and community is broken down, simplified into, and replaced by a global discourse of LGBT categories. As more LGBT people explode onto the world stage and in Beijing, global 
and local queer, non-LGBT sexualities, and gender identities conform to LGBT categories. In allowing for the physical presence of LGBT queer people while destroying non-LGBT spaces, gentrification as a policing mechanism comes in the form of "educating" local queer bodies into "normal" LGBT bodies.

There is a difference in the "normal" LGBT and the "perverse" queer. Cynthia Weber (2016) charts the proliferation of the LGBT as a "normal" category which became globalized as such with Hillary Clinton's Gay Rights are Human Rights speech. The LGBT citizen is figured as a homonormative, neoliberal, consuming, family-valued, (inter)national person; in contrast, the queer person, who does not conform to the strict categories of Lesbian, Gay, Bisexual or Transgender, is figured as deviant and needing to be fixed-for us this means gentrified. This is particularly interesting in two ways: firstly, "normal" LGBT folks are still subject to some forms of social discrimination, and secondly, gentrification processes that are designed to remove local queer built spaces, like Kai, are being transitioned into legally regulated LGBT spaces. This allows security relations to be built and fixed; the Chinese national vs. the Chinese local queer person vs. the Gay/LGBT tourist. Each of these relations is evaluated based on their economic value.

The club, Destination, provides a good example of looking through relations on forms of queer identities and their intersections with globalization and gentrification. The first relation I will analyze is the Chinese national vs. the Chinese queer. My mother, who is originally from Beijing and lived in this area, tells me that Sanlitun was the site of industrial and residential buildings, which is the opposite of what it is now. Sanlitun Village 三里屯, where Destination is adjacent to, was respacialized through gentrification as a shopping and tourist complex for the "New China." Sanlitun now is home to the famous Taikoo Li 太古里 and SanlitunSOHO 三里屯 shopping malls (though they are more like one vast street complex of 
stores), a vast majority of foreign embassies to China, multicultural recreational sites and numerous bars and nightclubs that light up what is colloquially called “Bar Street" 酒吧街. This appears to be a successful application of the $11^{\text {th }}$ Five-Year Plan (2005-2010), which expressed that one of its goals was to turn China's capital into a global city, along with the idea of becoming an appealing travel destination (Martínez 2016, 48). Alongside Sanlitun, other communities mentioned in this article have all been subject to regimes of gentrification that have been rationalized by the same logic in the $11^{\text {th }}$ Five-Year Plan, yet northeastern Beijing's own gentrification, alongside other parts of Beijing, have brought in new regimes of legalities. Destination is the only licensed gay club in the newly built Sanlitun Village, yet Sanlitun is increasingly unwelcoming to queer communities. To get to Destination either involves walking from Sanlitun, which is accessible to LGBT tourists, or ordering a Didi 滴滴, a ride-hailing service like Uber, to the nearest straight club (which is across the street from Destination) and then walking. The placement of Destination, across the street from these clubs, so close to the Workers Stadium speaks to the activities in which 'the people', who are figured as China's patriotic and consuming nationals, partake in this new China, where queer people are marginalized from participating in full.

The proliferation of LGBT discourse under increasing globalization becomes the basis for the possibility of their acceptance in Chinese society. However, the second relationship, the LGBT tourist vs. the local queer person, also intersect at Destination. Queer youth are forced to translate their identities into LGBT ones, and yet still find themselves subject to regimes of policing. Destination's primary customer is an older and financially dependent LGBT tourist. Their presence at Destination is psychologically built to "improve" younger queer folks through the emulation of the global LGBT identity. This logic assumes that acceptance within greater Chinese 
society through translating of queer identities into LGBT ones is part of a wider national performance in the achievement of national goals, but for this very reason, Destination has never been popular with younger queer people in Beijing and is increasingly being disassociated with by that group. Furthermore, the relationship between queer youth in Beijing and the global LGBT is challenged when noting that local queer bodies may not be explicitly policed in China anymore. However, the rise of the technological police state has transversed into new forms of policing that oversee the demolition of informal queer spaces as a form of social control under the guise of social etiquette, but are ultimately done to make way for institutions like Destination which are designed to 'fix' queer bodies. Local queer nightclubs and spaces are areas of solidarity and rebellion, and Destination's purposeful closing at 2 am as a form of social policing of queer bodies is even more evident and unmistakable considering the (straight) nightclubs in Sanlitun remain open until 6 am. Thus, the relationship between the LGBT and queer youth intersect in violent ways where queer youth see that spaces for themselves are being demolished to make room for new spaces for themselves that they never really wanted-and that these new spaces are filled with non-locals and arbitrary rules that are designed to hinder their solidarity and socialization.

If the gentrification of Beijing's northeast for relies on the normalization of local queer cultures, solidarity, and spaces through LGBT discourse, then it speaks to how the formations of the postindustrial city which promise freedom and liberty are counterintuitive since they demand conformity to categories that have been predetermined by Western interests. It also speaks to the violence that the normalization of global LGBT discourse means for local queer comm unities around the world. This also means that the ways in which we begin to critique other nations' ways of respecting other bodies must account for power interests. However, all 
understandings of power relations also recognize the constantly shifting nature of reclaiming identity, and as I conclude this article, I will go into the ways that Beijing's queer communities are countering global hegemonic forces that demand their gentrification.

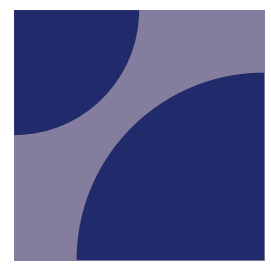

\section{From Solidarity to Slaughter to Survival}

The physical gentrification of places like Dongsi and Sanlitun resulting in the removal of informal spaces for queer people, such as Kai, is not unlike other forms of demolition around the world that are unequally applied onto the backs of queer people. In Toronto, we are seeing the closing of some of Church-Wellesley's most famous gay clubs in the name of gentrification. In response, newer collectives like Yohomo and New Ho Queen are appearing in the reclamation of the queer space, understanding that the gay club is no longer a possibility. Solidarity amongst queer communities in Toronto and Beijing speaks to a broader global process of how queer transnationalism intersects with the globalization of capitalist gentrification practices. Queer bodies are not necessarily accepted bodies, and they are saturated with prejudice that demands they conform. China's rise has come with gentrification of urban spaces in the name of modernity, which are part of international capitalist trends that have engendered a set of conforming demands along lines of consumption, but also of sexuality. Party rule, which is based on developmental performances, employs gentrification as a ruling mechanism at the expense of difference in queer spaces. This runs against a development for all message, that the Chinese Communist Party espouses, by disallowing the materialization of diverse sexuality, gender, and expression.

For the international and its repercussions, the rise of China and these performances appear 
as justification for other developing nations that their development does not need to follow the Western Model, one defined by free trade and small government, which are known to infringe upon statesovereignty. Western capitalism and sovereignty in a global capitalist system are deeply affected by flow dynamics in the capital and migration, which in turn are deeply affected by international economic trends (Sassen 1991). This Western model does not afford queer bodies valid spaces because it also pursues a model of gentrification that ties spaces to economic value.

The Chinese model of urban development utilizes the same properties of land value and speculation that western cores utilize in the performance of the modern, shining, glimmering, and bustling city, but uses its social credit system as a form of homogenizing its population while breaking down the autonomy of Chinese citizens from state forces. Both these models tear down marginalized peoples' housing and communities for the creation of spaces designed for a neoliberal cosmopolitanminded milieu, leading to developmental patterns that do not allocate resources on the basis of the recognition of different expressions in society. Both systems are actually not that different, because economic, environmental, and human rights are not afforded to all bodies. The gentrification of queer youths' spaces is viewed as an act of kindness by the central government, given to them by the benevolent state. In queer youths' experience, benevolence is a mode of violence that seeks to alter their socialization by policing and changing their spaces of expression, ultimately showing how successful gentrification is one that creates conformity most of all.

The gentrification of spaces is a mode of the de-socialization of queer communities, and in turn, queer communities around the world are looking to the Internet as a space that can be claimed, and where group consciousness can be developed. In 
Beijing this has manifested in gathering in informal spaces, such as Kai and Zhaodai, as physical spaces to memorialize an untold queer history that is being removed from Chinese Internet servers at breakneck speeds. The Beijing LGBT Center is memorializing local queer artists and migrants lost in the gentrification of 798 and throughout China by organizing physical socialization as queer histories become increasingly more challenging to uncover. At present the Chinese government has an implicit Three Noes Policy toward the local queer community-no approval, no disapproval, no promotion (不支持，不 反对, 不提倡 | bù zhīchí, bù fănduì, bù tíchàng), which is a policy that acts as though local queer identities do not exist. However, as LGBT discourse aligns with China's global ambitions, the normalization of samesex relationships is becoming increasingly prominent on ads, which can only happen in conjunction with the rules set out by the state-media apparatus. In countering the realization of queer group consciousness, gentrification is being weaponized as a measure for a class of Chinese citizens deemed worthy of state performances and modernity, of which queer people are not considered worthy.

In responding to their forced conformity in an artificial Chinese social space carved out by gentrification, queer people in Beijing are using class signifiers as a way of controlling their narratives. English knowledge in China is genuinely sought after and has become a class signifier-parents of wealthy children will enroll their children in English language classes from a young age. The use of English by a large portion of queer people in Beijing stems from the profound use of symbolism as an identification mechanism that has become globalized due to Western, English-language, queer popular culture. This plays a role in queer youth in Beijing imagining themselves as part of an international milieu. The widespread use of VPNs to access shows like Pose, a show about the complexities and nuances of the New York City ball scene in the 1980s, further backs the 
idea that youth are looking to the international in their reflexivities and subversities. From my discussion with one partier about Pose, he shared that it led to him learning how to do Waacking, a dance style that arose in racialized queer communities in Los Angeles in the 1970s. It is slowly becoming an alternativemainstream dance style amongst Chinese youth, with Waacking competitions being held throughout Beijing for all to participate in. On the same night we went to Zhaodai, one of my friends pulled out a packet of Lucky Strikes, a cigarette brand that in recent days, has carried a connotation of freedom for youth due to the song of the same name by Troye Sivan, a singer who is gay. The chorus, "'Cause you're safe like spring time/Short days, long nights, boy/Tell me all the ways to love you/'Cause you taste like Lucky Strikes/ You drag, I light, boy/Tell me all the ways to love you," definitively marks it as a queer anthem. Eventually, I asked him whether he liked Troye Sivan-and he said no, but that he did go to his Shanghai concert in 2019. Sivan came out in public on YouTube in 2013, which instantly turned him into a globalized LGBT figuration. This symbolism is only accessible with an ability to comprehend the English language. These symbols are mainstream amongst the queer communities in Beijing who are taking advantage of the explosion of LGBT discourse to claim their own local spaces. However, the co-opting of the English language-as-class-signifier, which is fortified by access to foreign media by queer communities, is a result of repurposing the artificially developed fetishization of English as a means of civility. In this way, reiterating gentrification practices is becoming more and more unstoppable, yet language, transnational ties and co-opting LGBT globalization offers the opportunity for local queer people around the world to organize against their forced translation into LGBT discourse. 


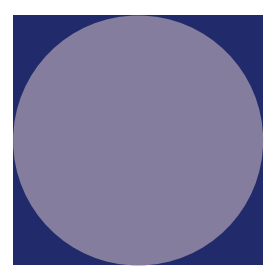

\section{Conclusion}

Gentrification begs us to wonder how local queer youth are playing a role in building this new China, even though their spaces and identities are being challenged through gentrification of their spaces and bodies. The internationalization of China has given new symbols to the Beijing queer community, whether the central government chooses to control Internet access or not. These symbols are coming together with their homegrown ones, such as with Ren Hang. Queer youth in Beijing are making a reflexive claim as part of a cosmopolitanminded generation that recognizes the transnational nature of its existence. Queer youth in Beijing are reterritorializing themselves within a dominant territory carved out by hegemonic gentrification by giving themselves the tools they need to fit into a high position in Chinese society. They get well-paying jobs, however, their queer existence, whether kept secret from family and working circles or not, subverts strict definitions of new class developments created and normalized by gentrification in capitalist China. Northeastern Beijing is a hotbed of queer activism and community-building that is looking to the inter and transnational and the local against gentrification, and these youth have proven their capability and are deserving of their autonomy.

\section{Acknowledgements}

I am grateful to the many individuals in Beijing for whom this piece is for, and for who have allowed me to find a home in place that I've considered home for a while but has become more foreign as a result of my years of distance. I would like to firstly thank the Asian Institute at the University of Toronto for supporting this work. I want to thank Dr. Dylan Clark for his unending belief and passion for his students, of which I consider myself humbled and lucky to be 
included. As well, I want to thank Dr. Joel Faflak for his suggestions towards the final structure and content of this piece, as well as the lively conversations we continue to have every week. Finally, above all else, I would also like to thank my 妈 for her support and belief in me. There is no word in the English language that adequately captures the amount of gratitude, love and respect I have for her and her ability to make everyone around her feel valued, not less her children.

\section{References}

Florida, R. (2012). The rise of the creative class, revisited. New York: Basic Books.

Glawe, L. \& Wagner, H. (2019). China in the Middle-Income Trap? China Economic Review 2019. https://doi.org/10.1016/j. chieco.2019.01.003

Huang, Y. (2015). Can Chinese escape the middle-income trap? China Economic Journal, 9(1), 17-33.

Kane, A. (2015). Ren Hang on nature, nudity and censorship. Dazed and Confused Magazine.

Li, W., \& Yang, D. (2005). The Great Leap Forward: Anatomy of a Central Planning Disaster. Journal of Political Economy, 113(4), 840-877.

Martínez, P. (2016). Authenticity as a challenge in the transformation of Beijing's urban heritage: The commercial gentrification of the Guozijian historic area. Cities 59, 48-56.

Sassen, S. (1991). The Global City. Princeton: Princeton University Press.

Weber, C. (2016). Queer International Relations: Sovereignty, Sexuality, and the Will to Knowledge. Oxford: Oxford University Press.

Wood, S. (2016). Migration, Mobility and Marginalisation: Consequences for Sexual and Gender Minorities. Institute of Development Studies (IDS) Policy Briefing 118.

Zhou, H. (2018). Will China Avoid the Middle-Income Trap? The Chinese Economy, 51(6), 483-502. 